\title{
BUDAYA SPIRITUAL KESULTANAN BANJAR: Historisitas dan Relevansinya di Masa Kini
}

\author{
Kamrani Buseri*
}

\begin{abstract}
This paper discusses about the spiritual culture in Kesultanan Banjar seeing from the bistorical perspective and its relevancy with the life today. The spiritual culture in banjar society can be seen from life cycle since birthday till die. Many of them were modified and fitted with the Islamic teaching. So that, the Islamic dimension is more explicit that the culture one. Kesultanan in varies cultural events ought to make the understanding to the society that Kesultanan Banjar is very concern to the spiritual culture and give the meaning for a material culture developing in many aspect of life. Besides, in any opportunity it may put the strength spiritual culture programm in order to be implemented in many sides of development.
\end{abstract}

Kata kunci: Islam Banjar, kesultanan Banjar, budaya spiritual, budaya material.

\section{Pendahuluan}

Bukti sejarah menjelaskan bahwa kerajaan Islam Banjar tidak bisa dipisahkan dengan bangkitnya budaya spiritual karena sejak berdirinya, Islam resmi menjadi agama kerajaan yang diikuti dan dianut oleh seluruh lapisan masyarakat sekaligus menjadi identitas mereka sehingga suku Banjar identik dengan Islam. Sejak itu pula masyarakat meninggalkan kepercayaan sebelumnya yakni animisme maupun Hindu.

Pangeran Samudera sebagai raja pertama memakai nama dan gelar baru yakni Sultan Suriansyah, dan semenjak itu pula muncul istilah kesultanan Banjar. Sejak berdirinya kesultanan Islam Banjar itu, sebenarnya budaya yang dikembangkan oleh kesultanan lebih menekankan pada budaya spiritual

*Guru Besar Ilmu Pendidikan Islam, pengajar Ilmu Pendidikan Islam, Filsafat Ilmu dan Manajemen Pendidikan Islam pada Pascasarjana IAIN Antasari, Ketua Dewan Pengawas Syariah Bank Kalimantan Selatan, Asesor Badan Akreditasi Nasional Perguruan Tinggi (BAN PT), dan Ketua Dewan Penasehat MUI Kalimantan Selatan. 
(Islam), meskipun tidak meninggalkan budaya material karena Islam adalah agama seimbang tetapi budaya spiritual tetap sebagai fondasinya.

Budaya spiritual sangat penting untuk dihidupkan, dikembangkan dan dihayati oleh semua lapisan masyarakat lebih-lebih bagi kalangan generasi muda sekarang, di saat budaya material sedang mendominasi. Budaya spiritual perlu dikembangkan agar mampu mengimbangi laju pesatnya budaya material sejalan dengan berkembang pesatnya faham skuler-pragmatis saat ini. Berkembangnya budaya material tanpa diilhami oleh budaya spiritual melahirkan masyarakat materialis, hidonis dan pragmatis. Akibatnyal, harkat martabat sebagai umat dan bangsa tereliminasi oleh kecenderungan kesenangan sesaat, jangka pendek serta tidak berorientasi ukhrawi. Padahal Allah telah mengingatkan dalam surah Dhuha ayat 4, bahwa yang ukhrawi jauh lebih baik dari yang duniawi.

Masyarakat Banjar yang dikenal religius harus terus dipupuk. Artifak utama seribu mesjid dan langgar, sejumlah pesantren dan madrasah menjadi sarana utama pengembangan budaya spiritual. Ini harus dipertahankan tetapi tentu saja melalui modifikasi dan rekonstruksi sehingga mampu menjadi penyangga perkembangan budaya masyarakat di era kontemporer ini.

Batamat Quran dengan segenap perangkatnya adalah bagian penting cara pandang Sultan dan masyarakat terhadap Alquran sebagai pedoman hidup umat manusia. Masyarakat Banjar dikenal hebat membaca Alquran dan sanggup menjadi imam salat, budaya ini harus dilestarikan, sehingga orang Banjar di zamannya selalu berada di depan karena terbiasa menjadi imam salat. Karakter ini memudahkan orang Banjar menjadi pemimpin di lapangan yang lebih luas.

Disisi lain Prof. Dr. H. A. Mukti Ali pernah berkomentar bahwa ulamaulama orang Banjar hebat-hebat dalam bahasa Arab. Ini simbol lain dari tingginya budaya spiritual yang mampu mengarahkan masyarakat menuju kesimbangan dalam hidup budayanya (spiritual dan material) untuk menggapai ridha Allah swt di dunia dan akhirat kelak. Disamping itu seorang ulama sangat diapresiasi oleh masyarakat atas dasar penguasaan mereka terhadap Kitab Kuning yang berbahasa Arab gundul.

\section{Corak Ragam Budaya Spiritual Masyarakat Banjar}

Budaya spiritual merasuk dalam berbagai aspek kehidupan masyarakat Banjar, sebagai contoh apa yang diketengahkan M. Rifhan dalam tulisannya di Harian Media Kalimantan tanggal 28 Nopember 2011, dengan mengutip Tri 
Hayat AW bahwa rumah panggung dibangun oleh urang bahari menggunakan konsep-konsep budaya Banjar yang religius dan sarat makna serta filosofi. Lihat saja tentang filosofi religi dan budaya pada pembangunan rumah bubungan tinggi menjulang kelangit merupakan tanda ikrar pengakuan terhadap Allah swt. Bagian atas bangunan rumah Banjar bersudut lima merupakan manifestasi rukun Islam yang berjumlah lima. Unsur hitungan panjang, lebar dan tinggi harus ganjil karena sesuai dengan sifat dan nama Allah swt yang berjumlah ganjil, dan Allah menyukai bilangan ganjil. Belum lagi pada ornamen-ornamen rumah panggung yang kaya akan makna dan simbol keseimbangan hubungan antara, manusia, alam dan Sang Pencipta.

Berkenaan dengan budaya spiritual ini juga tampak pada siklus kehidupan masyarakat Banjar semenjak kelahiran hingga kematian. Ada beberapa diantaranya yang sehari kesehari telah dimodifikasi dan disesuaikan dengan ajaran Islam, sesuai perkembangan ilmu pengetahuan keislaman masyarakat saat ini, sehingga lebih menonjol aspek Islamnya bukan lagi budayanya. Namun demikian beberapa bagian tertentu yang dianggap hanya asesores dibiarkan berkembang hingga saat ini. Acara mandi tujub bulan kehamilan, batampung tawar, batumbang, baayun anak. Baayun anak sebagian tidak dikerjakan lagi, tetapi di Banua Halat Tapin dilestarikan dengan baik.

Prof. Dr. Alfani Daud ${ }^{1}$ dengan sangat baik dan lengkap menguraikan aspek-aspek budaya masyarakat Banjar dikaitkan dengan siklus kehidupan dan mata pencaharian. Berkenaan dengan menanam padi misalnya digambarkan beliau di beberapa daerah, masyarakat Banjar saat mau manaradak (menyemai). Ada sementara masyarakat yang melakukan bulir-bulir padi dirabun yaitu diasapi di atas api parapen dengan asap menyan sambil mengucapkan "kur sumangat" berkali-kali. Ketika memasukkan padi ke dalam air dibacakan surah Fatihah sekali dan selawat 3 kali. Ada pula sementara masyarakat yang saat mau memasukkan benih padi ke lobang tugal dibacakan tasbih diulangai sampai lobang atau umang ke tiga. Pada saat penanaman padi di sawah biasanya keluarga petani menyiapkan bubur tepung beras yang dinamakan kokoleh, yang akan dimakan bersama di tengah sawah setelah upacara selesai dan sebelum melanjutkan kegiatan menanam selanjutnya. Kokoleh selalu diasosiasikan dengan bapakuleh atau memperoleh hasil.

${ }^{1}$ Alfani Daud, Islam \& Masyarakat Banjar: Diskripsi dan Analisis Kebudayaan Banjar, (Jakarta: PT. RajaGrafindo Persada, 1997). 
Pada aspek lain saat mau menuai padi di sawah misalnya, biasanya didahului dengan tapung tawar juga semacam memanggil semangat padi, karena padi dianggap memiliki semangat seperti kehidupan. Ada istilah kuur sumangat dan padi bisa menangis bila cara memanen tidak baik sehingga ada padi yang lepas dan terbuang begitu saja. Seringkali orang tua memberi nasehat kepada anaknya bahwa satu butir padi itu sangat berharga karena meskipun hanya satu butir tetap baru didapatkan dengan memakan waktu selama satu tahun, sehingga perlu hati-hati jangan sampai ada yang terbuang percuma meskipun hanya satu butir saja.

Padi sebagai bahan makanan pokok manusia memiliki hubungan spesialis yang menunjukkan keharmonisan hubungan antara alam dengan manusia. Tidak seperti sekarang sesuai dengan perkembangan hubungan manusia dengan alam dimulai dengan hubungan erat atau menyatu antara alam dengan manusia di zaman mitologis, kemudian manusia terpisah dengan alam di zaman positivis, bahkan manusia berhubungan secara fungsional dengan alam yang membikin semakin berjaraknya antara alam dengan manusia, dan alam semaunya diekpolaitasi oleh manusia. Akibat negatifnya sudah banyak dirasakan oleh manusia, karena manusia lupa bahwa dirinya juga adalah bagian dari alam. Alam yang tidak memiliki akal pun bilamana dijajah oleh manusia, mereka juga akan membalas. Hutan digunduli secara berlebihan sehingga ekologi menjadi rusak akibatnya alam mulai memberontak dengan banjir besar yang mengerikan manusia. Rumah kaca yang berlebihan merusak uzon, dimana sinar matahari mulai berbuat keras juga kepada manusia.

Batapung tawar yaitu selamatan setelah melahirkan, umumnya sudah diganti dengan aqiqah yang dianjurkan oleh Rasulullah saw, yakni penyembelihan kambing dua ekor untuk anak lelaki dan satu ekor untuk anak perempuan. Kambing dimasak dan diadakan upacara dengan mengundang tetangga dan kaum kerabat. Dalam upacara aqiqah ini terkait acara pemberian nama (tasmiah), mencukur rambut anak (tabliqah) yang rambutnya ditimbang dengan emas (dalam hadits dengan perak) yang dinilai dengan uang kemudian dibagikan kepada fakir miskin, mencelupkan kurma ke mulut anak (tabnikah) oleh seorang yang saleh dengan harapan semoga anak tersebut kelak menjadi orang saleh pula. Di masyarakat Banjar seringkali bukan kurma yang dicelupkan tetapi mencelupkan kelapa dicampur gula merah dan garam dengan maksud agar anak kelak berbicara dengan lemak manis disenangi temana-temannya dan kalau sudah besar disenangi oleh masyarakat. 
Pada budaya Banjar dulu sangat harmonis hubungan antara manusia, alam dan Tuhan. Budaya Banjar masa kini hendaknya menyimak hal ini untuk kembali melakukan harmonisasi hubungan ketiganya tentu melalui modifikasi sesuai dengan perkembangan pemikiran dan pengetahuan masyarakat saat ini.

\section{Infiltrasi Budaya Sekuler-Pragmatis}

Tidak bisa dimungkiri, karena masyarakat Banjar berada tidak di ruang hampa, maka mereka mau atau tidak mau, langsung atau tidak langsung bersentuhan dengan budaya yang berkembang di belahan bumi ini. Infilterasi faham skularisme dan pragmatisme tidak bisa dinapikan, justru masyarakat telah terimbas dengan dua trend budaya tersebut. Dapat dibuktikan bagaimana perilaku masyarakat saat menghadapi pemilu, bagaimana perilaku ekonomi masyarakat yang serakah dan terlalu mementingkan duniawi dibanding ukhrawi, atau agama difahami sebagai penopang kehidupan materi, bukan sebaliknya agama mengarahkan perilaku ekonomi.

Skularisme yang bercirikan utamanya mementingkan yang duniawi mengabaikan yang ukhrawi adalah penopang budaya material sekaligus menjauhkan budaya spiritual. Bagi skularis sesuatu yang bermanfaat adalah yang duniawi bahkan bagi skularis-positivis, mereka meniadakan hal-hal yang ukhrawi dan spiritual.

Begitupula bagi mereka yang menjunjung tinggi pragmatisme, sesuatu dianggap benar bilamana bermanfaat praktis bagi dirinya walaupun berdampak negatif bagi masyarakat luas serta meskipun bertentangan dengan logika formal, logika ilmiah dan logika absolut.

Faham skularisme melahirkan manusia yang tidak mengimani hari akhirat, begitupula pragmatisme melahirkan manusia yang tidak memiliki integritas karena diarahkan oleh budaya kebermanfaatan bagi dirinya meskipun merugikan orang lain.

Apabila kedua faham besar budaya material tersebut telah meresap tanpa ada kritikan oleh budaya spiritual, apa yang bakal terjadi pada masyarakat kita, budaya individualistik-kompettitif akan tumbuh subur. Ujung-ujungnya kekompakan dan kebersamaan kita mudah tergoyahkan yang kemudian berakibat rendahnya martabat sebagai orang Banjar.

Budaya gotong royong dari masyarakat desa sebelum kemerdekaan dulu seperti gotong royong masyarakat untuk mengirim anak-anak tertentu untuk studi ke Jawa maupun ke Mesir sudah tidak terdengar lagi beberapa puluh tahun terakhir hingga saat ini. 
Infiltrasi budaya skuler sejalan dengan berkembangnya ilmu pengetahuan dan teknologi, Ilmu pengetahuan telah membebaskan manusia dari serba tuhan. Dahulu orang percaya bahwa alam -- matahari beredar, bulan bersinar -diatur oleh Tuhan atau dewa tertentu. Setelah ditemukannya hukum alam, segala peristiwa alam telah diterangkan oleh hukum yang sudah melekat padanya yang dapat difahami oleh akal manusia. ${ }^{2}$

Akibat pembebasan di atas, manusia merasa kurang terikat dengan Tuhan (agama).

Hal Itu ada kaitan dengan pengetahuan ilmiah itu strukturnya rasional, isinya empirik dan sipatnya skuler. ${ }^{3}$

Pada iftitah wawasan MUI digambarkan bahwa:

"Disisi lain, saat ini umat Islam Indonesia menghadapi tantangan global yang sangat berat. Tantangan tersebut antara lain berupa ideologi liberalisme kapitalisme yang berpangkal pada sekularisme dengan sistem politik dan sistem ekonomi yang sering dipaksakan berlaku dinegerinegeri lain, kemajuan pengetahuan dan teknologi yang dapat menggoyahkan batas etika dan moral, serta budaya global yang didominasi Barat dan bercirikan pendewaan diri, kebendaan, dan nafsu syahwatiyah yang potensial melunturkan aspek religiusitas masyarakat, serta meremehkan peran agama dalam kehgidupan umat manusia". ${ }^{4}$

Perkembangan ilmu pengetahuan sedikit demi sedikit mengganti kedudukan takhayul dan agama. Ilmu pengetahuan dan teknologi dapat pula menggantikan ideologi yang dianut. Ideologi lain dianggap penghambat demi pencapaian kemajuan dan kesejahteraan, demikian pula agama sehingga menimbulkan konflik-konflik. ${ }^{5}$

Itulah gambaran ilfiltrasi budaya skuler-pragmatis melalui nilai ikutan ilmu pengetahuan dan teknologi secara umum, tetapi memang diakui pula bahwa ilmu pengetahuan dalam konteksnya dengan ilmuan yang melahirkannya, diantara mereka masih ada yang mempercayai adanya Tuhan

2A.B, Shah, Metodologi Ilmu Pengetabuan, (Jakarta: Yayasan Obor Indonesia, 1986), h. 12.

${ }^{3}$ A.B, Shah, Metodologi Ilmu Pengetahuan ..., h. 70.

${ }^{4}$ Sekretariat Majelis Ulama Indonesia Pusat, Pedoman Penyelenggaraan Organisasi Majelis Ulama Indonesia, Edisi Revisi 2011 (Hasil Rakernas MUI Tahun 2011), (Jakarta, 2011), h. 5.

${ }^{5} \mathrm{~T}$ Jacob, Manusia Ilmu dan Tehnologi, Pergumulan Abadi dalam Perang dan Damai, (Yogyakarta: Tiara Wacana, 1988), h. 9. 
sebagaimana terlontar dari Enstien. Namun ilmu pengetahuan yang tampak hingga kini, di satu sisi membebaskan manusia dari hal-hal yang negatif, tetapi di sisi lain mengikat manusia begitu ketat hingga melahirkan mazhab scientis yang seakan-akan mempertuhankan ilmu pengetahuan.

\section{Teknologi Mutakhir dan Keruntuhan Peradaban}

Hakikat teknologi pada mulanya untuk membantu manusia merubah lingkungan agar bermanfaat bagi kehidupan manusia. Berkembangnya temuan di bidang sains maka kemajuan bidang teknologi juga semakin canggih, akhirnya manusia hampir-hampir tidak mengenal lagi hasil kreasinya sendiri serta tidak mampu lagi mengendalikan hasil ciptaannya.

"Ilmu pengetahuan dan teknologi tumbuh dan berkembang dengan cepat melebihi daya serap otak manusia, sehingga tidak dapat memahami seluruh produk ilmu pengetahuan kendatipun sudah memakainya, bahkan menjadi objeknya. Manusia terpragmentasi oleh ilmu pengetahuan sehingga tidak utuh lagi, demikian pula alam lingkungannya. Mula-mula dengan ilmu pengetahuan dan teknologi manusia hendak menguasai alam dan sampai batas-batas tertentu, tetapi ia lupa bahwa ia sendiri adalah bagian dari alam dan turut terkuasai oleh ilmu pengetahuan". ${ }^{6}$

Teknologi dewasa ini sudah berada pada pase ke tiga atau tahap puncak. Pada pase pertama manusia langsung menggunakan bahan tehnik dari alam pada zaman batu. Pada pase kedua manusia telah merubah bahan alam kepada hal-hal baru, sedang pada pase ketiga manusia telah menemukan teknologi mesin yang membawa kepada peradaban mesin ${ }^{7}$. Bahkan lebih puncak lagi dengan menyatunya antara ilmu pengetahuan dan teknologi, atau sebaliknya teknologi mendorong ilmu pengetahuan hingga teknologi peralatan keras telah banyak ditinggalkan oleh teknologi perangkat lunak.

A. Fatih Syuhud, ${ }^{8}$ mengemukakan berikut ini. Teknologi modern telah memungkinkan terciptanya komunikasi bebas lintas benua, lintas negara,

${ }^{6} \mathrm{~T}$ Jacob, Manusia Imu ..., h. 9.

${ }^{7}$ Sutarjo Adisusilo JR, Problematika Perkembangan Ilmu Pengetahuan, (Yogyakarta: Yayasan Kanisius, 1983), h. 102-03.

${ }^{8}$ A. Fatih Syuhud, Tantangan Pendidikan Islam di Era Globalisasi September 6, 2005, Posted by Fatih in Artikel Opini, Islam. trackback Catatan: Tulisan ini dimuat di Jurnal VISI, PPI-India dan Sidogiri.com.) 
menerobos berbagai pelosok perkampungan di pedesaan dan menyelusup di gang-gang sempit di perkotaan, khususnya televisi, dapat dijadikan alat yang sangat ampuh di tangan sekelompok orang atau golongan untuk menanamkan atau, sebaliknya, merusak nilai-nilai moral, untuk mempengaruhi atau mengontrol pola fikir seseorang oleh mereka yang mempunyai kekuasaan terhadap media tersebut. Persoalan sebenarnya terletak pada mereka yang menguasai komunikasi global tersebut memiliki perbedaan perspektif yang ekstrim dengan Islam dalam memberikan criteria nilai-nilai moral; antara nilai baik dan buruk, antara kebenaran sejati dan yang artifisial. Adanya perbedaan perspektif terhadap nilai-nilai etika dan moralitas agama, jargon saintis sebagai pencari kebenaran tampaknya perlu dipertanyakan. Hal itu bisa diikuti contoh berikut: Di Amerika Serikat, di akhir tahun 40-an, anak-anak remaja diberi sarapan yang dicampuri radioaktif, ibu-ibu setengah baya disuntik dengan plutonium radioaktif dan biji kemaluan para tahanan disuntik radiasi semua atas nama sains, kemajuan dan keamanan. Eksperimen-eksperimen ini diadakan sejak tahun 1940-an sampai 1970-an (Brown, 1994).

Selama tahun 1950-an, 60-an dan 70-an, menurut New York Times, wajib bagi seluruh mahasiswa baru, laki-laki dan perempuan, di Harvard, Yale dan universitas-universitas elit lain di Amerika, difoto telanjang untuk sebuah proyek besar yang didisain dalam rangka untuk menunjukkan bahwa 'tubuh seseorang' yang diukur dan dianalisis, dapat bercerita banyak tentang intelegensia, watak, nilai moral dan kemungkinan pencapaiannya di masa depan. Ide ini berasal dari pendiri Darwinisime Sosial, Francis Galton, yang mengajukan foto-foto arsip tersebut untuk dewan kependudukan Inggris. Sejak awal tujuan dari pemotretan-pemotretan ini adalah egenetika. Data yang terakumulasi akan dipakai sebagai proposal untuk 'mengontrol dan membatasi produksi organisme dari orang-orang yang inferior dan tidak berguna'. Beberapa organisme tipe terakhir ini akan dikenakan sangsi bila melakukan reproduksi atau akan disteril (Rosenbaum, 1995).

Sementara itu media televisi, sebagai hasil pencapaian teknologi modern yang paling luas jangkauannya memiliki dampak sosio-psikologis sangat kuat pada pemirsanya. Beberapa hasil studi berhasil menguak hubungan antara menonton televisi dengan sikap agresif (Huismon \& Eron, 1986; Wiegman, Kuttschreuter \& Baarda, 1992), dengan sikap anti social (Hagell \& Newburn, 1996), dengan sikap aktifitas santai (Selnon \& Reynolds, 1984), dengan kecenderungan gaya hidup (Henry \& Patrick, 1977), dengan sikap rasial (Zeckerman, Singer \&Singer, 1980), kecenderungan atas preferensi seksual 
(Silverman - Watkins \& Sprafkin, 1983), kesadaran akan daya tarik seksual (Tan, 1979), stereotype peran seksual (Durkin, 1985), dengan bunuh diri (Gould \& Shaffer, 1986), identifikasi diri dengan karakter-karakter di televisi (Shaheen, 1983).

Memang hasil studi yang lain tentang dampak-dampak televisi menunjukkan indikasi yang cenderung 'agak menggembirakan'. Seperti adanya kesadaran akan segala peristiwa yang terjadi di seluruh dunia (Cairn, 1990), kesadaran akan hak dan kewajiban sebagai warga negara (Conway, Steven \& Smith, 1975), bertambahnya pengetahuan akan geografi (Earl \& Pasternack, 1991), meningkatnya pengetahuan tentang masalah politik (Furnham \& Gunter, 1983), bersikap pro sosial (Gunter, 1984).

Tetapi perlu dicatat bahwa sejak munculnya era televisi dibarengi dengan timbulnya berpuluh-puluh channel dengan menawarkan berbagai acara-acara yang menarik dan bervariasi, umat Islam hanya berperan sebagai konsumen, orang Baratlah (baca, non-Muslim) yang memegang kendali semua teknologi modern tak terkecuali televisi

\section{Penguatan Budaya Spiritual Sebuah Solusi}

Dari berbagai uraian sebelumnya cukup meyakinkan bahwa budaya spiritual harus disadari sebagai fondasi pengembangan budaya ke depan terutama dalam konteks memberi inspirasi, fondasi bagi pengembangan budaya material.

Kesulitan etis yang diketengahkan van Melsen justru etis yang difahami tetap terkungkung pada dataran filosofis, sedangkan jawaban-jawaban filosofis sendiri terhadap siapa dan apa sesungguhnya manusia berbeda-beda. Oleh sebab itu manusia harus berani melangkah lebih maju lagi yaitu menerima kenyataan - phenomenologis - tentang eksistensi agama yang telah memberikan kepastian mengenai siapa dan apa manusia. Tetapi menurut Nurcholish Madjid bukan agama sebagai kenyataan di masyarakat, tetapi yang dimaksud dengan agama di sini ialah dalam bentuknya yang mendalam dan universal (keagamaan an sich) bukan yang ada secara sosiologis, dan sebagai pangkal tolak penelaahan dan perenungan lebih lanjut diutarakannya:

1. Kebutuhan atas kepercayaan kepada Tuhan dengan segala atributnya.

2. Hubungan yang "personal" dan intim dengan Tuhan

3. Doktrin tentang fungsi-sosial harta kekayaan: tujuan hidup bukanlah pada terkumpulnya kekayaan itu tetapi pada cara penggunaanya untuk sesama manusia. 
4. Pengakuan yang pasti akan adanya hal-hal yang tidak dapat didekati secara empiris atau induktif, melainkan dengan cara deduktif atau "percaya".

5. Kepercayaan akan adanya kehidupan lain sesudah kehidupan historis (dunia) ini yang lebih tinggi nilainya.'

Memang menurut Jujun S Suriasumantri, ${ }^{10}$ agama pada satu sisi akan memberikan landasan moral bagi aksiologi keilmuan.

Budaya spiritual akan mampu menggiring masyarakat Banjar sesuai level dan status sosialnya untuk menjadi manusia yang memiliki integritas keimanan dan keperibadian dan pada gilirannya akan mampu mengasah aspek soft dimension $^{11}$ dari sumber daya manusia dari generasi ke generasi yang akan berperan dalam pembangunan ke depan.

Pembangunan SDM ke depan ditinjau dari sudut budaya, maka dimensi lunak dari manusia harus menjadi perhatian utama dibandingkan dengan dimensi keras yang antara lain pemilikan ilmu pengetahuan, keterampilan maupun kompetensi atau kemampuan lainnya dari SDM tersebut. Hal itu tentu dimulai dengan menguatkan budaya spiritual di atas budaya material.

\section{Penutup}

Atas pengalaman panjang sejarah budaya Banjar, keharmonisan hubungan antara manusia sebagai pencipta budaya dengan alam dan Tuhan sebagai pemilik alam semesta selalu terjaga. Corak budaya seperti itu adalah disebabkan karena budaya spiritual mampu menjadi penyangga budaya material.

Hubungan dengan alam pada fase mitologi dan hubungan dengan alam pada fase fungsional hendaknya terus menerus dikritisi dan diberi makna sesuai dengan ajaran agama sehingga terhindar dari praktik-praktik pengkudusan halhal yang tidak kudus dan penduniawian hal-hal yang ukhrawi dan berakibat menjadi unreligious.

Budaya spiritual sebagai fondasi dan referensi bagi budaya material sesuai dengan ajaran agama Islam yang menegaskan bahwa yang ukhrawi lebih baik

\footnotetext{
${ }^{9}$ Nurcholish Madjid, 1987, h. 154-155.

${ }^{10}$ Jujun S Suriasumantri, Filsafat Ilmu Sebuah Pengantar Populer, (Jakarta: Pustaka Sinar Harapan, 1987), h. 123.

${ }^{11}$ Soft dimension itu meliputi antara lain orientasi, motivasi, nilai, sikap dan simbol atau artifak. Apabila kelima aspek ini dituntun oleh pandangan spritual tentu akan berbeda bila dituntun oleh pandangan serba materi (materialisme).
} 
dari yang duniawi. Oleh sebab itu pola pandang masyarakat Banjar muslim adalah "dunia itu penting tetapi akhirat lebih penting".

Membangun budaya untuk melahirkan masyarakat yang sejahtera tentu tidak bisa hanya dengan pendekatan rasional semata, tetapi harus pula dengan pendekatan positivistik, penomenologik, dan transendental.

Kesultanan dalam berbagai event budaya seyogianya terus berupaya memberikan pemahaman kepada masyarakat bahwa Kesultanan Banjar sangat memperhatikan budaya spiritual untuk memberi makna bagi pengembangan budaya material dalam berbagai segi kehidupan. Dalam berbagai kesempatan bisa memasukkan program penguatan budaya spiritual ini agar terimplementasi di berbagai bidang pembangunan.

\section{Daftar Pustaka}

Daud, Alfani, Islam \& Masyarakat Banjar: Diskripsi dan Analisis Kebudayaan Banjar, Jakarta, PT. RajaGrafindo Persada, 1997.

Shah, A.B, Metodologi Ilmu Pengetahuan, Jakarta, Yayasan Obor Indonesia, 1986.

Sekretariat Majelis Ulama Indonesia Pusat, Pedoman Penyelenggaraan Organisasi Majelis Ulama Indonesia, Edisi Revisi 2011 (Hasil Rakernas MUI Tahun 2011), Jakarta, 2011.

Jacob, T Manusia Ilmu dan Tehnologi, Pergumulan Abadi dalam Perang dan Damai, Yogyakarta, Tiara Wacana, 1988.

Adisusilo JR, Sutarjo, Problematika Perkembangan Ilmu Pengetahuan, Yogyakarta, Yayasan Kanisius, 1983.

Syuhud, A. Fatih, Tantangan Pendidikan Islam di Era Globalisasi September 6, 2005, Posted by Fatih in Artikel Opini, Islam. trackback Catatan: Tulisan ini dimuat di Jurnal VISI, PPI-India dan Sidogiri.com.)

Madjid, Nurcholish, 1987.

Suriasumantri, Jujun S, Filsafat Ilmu Sebuah Pengantar Populer, Jakarta, Pustaka Sinar Harapan, 1987. 
